\title{
Sp1 downregulates proinflammatory cytokine-induced catabolic gene expression in nucleus pulposus cells
}

\author{
KANG XU ${ }^{1,2^{*}}$, XIAOFEI WANG ${ }^{2 *}$, QIANSHI ZHANG ${ }^{3}$, ANJING LIANG $^{2}$, \\ HAIPENG ZHU ${ }^{2}$, DONGSHENG HUANG ${ }^{2}$, CHUNHAI $\mathrm{LI}^{2}$ and WEI YE ${ }^{2}$ \\ ${ }^{1}$ Experimental Center of Surgery; ${ }^{2}$ Department of Spine Surgery, Sun Yat-sen Memorial Hospital, \\ Sun Yat-sen University, Guangzhou, Guangdong 510120; ${ }^{3}$ Department of Spine Surgery, \\ The Second Xiangya Hospital of Central South University, Changsha, Hunan 410011, P.R. China
}

Received June 7, 2015; Accepted August 22, 2016

DOI: $10.3892 / \mathrm{mmr} .2016 .5730$

\begin{abstract}
During the pathogenesis of intervertebral disc degeneration, pro-inflammatory cytokines, including tumor necrosis factor- $\alpha$ (TNF- $\alpha)$, stimulate the degradation of the extracellular matrix (ECM) of intervertebral discs via the activity of catabolic enzymes including matrix metalloproteinases (MMPs), disintegrins and metalloproteinases with thrombospondin motifs (ADAMTSs), and cyclooxygenase 2 (Cox2). The transcriptional promoters of the human catabolic enzymes MMPs, ADAMTS, Cox 2 and Syndecan 4 contain at least one specificity protein-1 (Sp1) transcription factor-binding site. The present study investigated the role of $\mathrm{Sp} 1$ in the regulation of the mRNA and protein expression of the aforementioned catabolic enzyme genes in nucleus pulposus cells, using reverse transcription-quantitative polymerase chain reaction, western blot, transfection and RNA interference. The data demonstrated that Sp1 transcription factor protein expression is induced by TNF- $\alpha$ and interleukin-1 $\beta$. Specific inhibitors of Sp1 DNA binding to its GC-rich consensus site, WP631 and mithramycin A, partially suppressed TNF- $\alpha$-induced catabolic enzyme expression and activity. Genetic inhibition of Sp1 by small interfering RNA-mediated Sp1 knockdown partially inhibited catabolic enzyme induction by TNF- $\alpha$. In addition, Sp1 transcription factor inhibitors decreased the activity of MMP3, ADAMTS4 and ADAMTS5 promoters. Furthermore, chromatin immunoprecipitation revealed functional $\mathrm{Sp} 1$ binding sites at $-577 /-567$ bp within the
\end{abstract}

Correspondence to: Dr Wei Ye or Dr Chunhai Li, Department of Spine Surgery, Sun Yat-sen Memorial Hospital, Sun Yat-sen University, 107 Yan Jiang Xi Road, Guangzhou, Guangdong 510120, P.R. China

E-mail: yewei3@mail.sysu.edu.cn

E-mail: chunhaili@163.com

\section{${ }^{*}$ Contributed equally}

Key words: intervertebral disc, intervertebral disc degeneration, inflammatory, specificity protein-1, tumor necrosis factor- $\alpha$
ADAMTS4 promoter and -718/-708 bp within the ADAMTS5 promoter. These results provide pharmacological and genetic evidence of the importance of Sp1 in catabolic enzyme gene regulation during TNF- $\alpha$ stimulation. Thus, Sp1 may represent an effective target in reducing intervertebral disc-associated ECM loss.

\section{Introduction}

The intervertebral disc lies between adjacent cartilaginous endplates in the spine and is composed of a gel-like core, termed the nucleus pulposus (NP), and the surrounding annulus fibrosus (1). In the NP, proteoglycan is the primary aggrecan, while collagen II is the primary collagen (2). Decreased levels of aggrecan and collagen II in the NP result in the initiation of intervertebral disc degeneration $(3,4)$. Tumor necrosis factor- $\alpha$ (TNF- $\alpha$ ) and interleukin 1- $\beta$ (IL-1 $\beta$ ) are the pro-inflammatory cytokines principally associated with the progression of intervertebral disc degeneration and have been previously demonstrated to increase the degradation of the extracellular matrix (ECM), including aggrecan and collagen II (5-7). Matrix metalloproteinases (MMPs), disintegrins and metalloproteinases with thrombospondin motifs (ADAMTSs) and cyclooxygenase 2 (Cox2) are the major catabolic enzymes associated with ECM degradation induced by pro-inflammatory factors in the intervertebral disc (6-10). Syndecan 4 (SDC4), a cell surface heparin sulfate proteoglycan, serves a major role in matrix catabolism through the activation of MMP3, ADAMTS4 and ADAMTS5 in the intervertebral disc $(6,7,10)$.

Mitogen-activated protein kinase (MAPK) inhibition can decrease the upregulation of MMP3, ADAMTS4 and ADAMTS5 expression induced by TNF- $\alpha$ and IL-1 $\beta(6,7,11)$. In addition, nuclear factor $\kappa$-light-chain-enhancer of activated $\mathrm{B}$ cells $(\mathrm{NF}-\kappa \mathrm{B})$ and SDC4 are involved in the signaling pathways in NP cells that mediate TNF- $\alpha$ and IL-1 $\beta$ induced aggrecan degradation by MMP3, ADAMTS4 and ADAMTS5 $(6,7,11)$. Similarly, the induction of MMP13 and Cox 2 expression by TNF- $\alpha$ and IL- $1 \beta$ is regulated through the MAPK and NF- $\kappa$ B signaling pathways $(12,13)$. Specificity protein-1 (Sp1) is an important transcription factor that contains a zinc finger DNA-binding domain, and binds to GC-rich regions in the 
promoters of genes to activate transcription (14). It is also involved in the expression of ECM-associated genes in various cells, including renal tubular epithelial cells and melanoma cells $(15,16)$. Inhibition of Sp1 and Sp1 knockdown has been previously demonstrated to partially inhibit ADAMTS4 and Cox 2 induction by IL- $1 \beta$ or Toll-like receptor 4 in chondrocytes $(17,18)$. However, the effect of the Sp1 transcription factor on the expression of catabolic enzymes induced by inflammatory cytokines in NP cells remains to be determined.

The aim of the current study was to examine the role of the $\mathrm{Sp} 1$ transcription factor in the regulation of TNF- $\alpha$-induced catabolic factor, including MMP3 and ADAMTS4, gene expression in NP cells.

\section{Materials and methods}

Plasmid constructs and reagents. Sp1 short hairpin RNA (shRNA) and plasmid (p)LKO.1 shRNA were provided by Dr Hyoung-Pyo Kim of Yonsei University College of Medicine (Seoul, Korea) (19). psPAX2, pMD2.G and pRL-TK plasmids were provided by Dr Dong Xiao of Nanfang Medical University (Guangzhou, China) (20). To assay the promoter activity, the 5'-flanking region of the MMP3, ADAMTS4 and ADAMTS5 genes was inserted into the firefly luciferase reporter vector, pGL3-Basic (Promega Corporation, Madison, WI, USA), which contained no eukaryotic promoter or enhancer element. To construct the promoter, genomic DNA was isolated from $293 \mathrm{~T}$ cells, which were provided by Dr Dong Xiao of Nanfang Medical University (20), using a Gentra genomic DNA isolation kit (Qiagen, Inc., Valencia, CA, USA). Polymerase chain reaction (PCR) was used to amplify the 2.3 kb MMP-3 promoter (MMP3-Luc, F 5'-GGCGCCTCG AGTTGACATTTGCTATGAGC-3'; R 5'-CAAGCTTGTCTT GCCTGCCTCCTTGTAGGT-3'); 2.1 kb ADAMTS4 promoter (ADAMTS4-Luc, F 5GCGTGCTAGCCCGGGCTCGAG GGTGGGTGATCCAGGAAGTG-3, R5'-CAGTACCGGAAT GCCAAGCTTAGTAGCAGAAGCAGCCACAC-3'); $2.2 \mathrm{~kb}$ ADAMTS5 promoter (ADAMTS5-Luc, F5'-GCGTGCTAG CCCGGGCTCGAGCCCCAGCGTAGCCAAAGTTA-3', R 5'-CAGTACCGGAATGCCAAGCTTGCTTTATCCTGG GCAGGTGT-3') with XhoI- and HindIII restriction enzyme digestive sites. The cycling conditions were as follows: An initial denaturation step at $94^{\circ} \mathrm{C}$ for 5 min was followed by 35 cycles of denaturation at $94^{\circ} \mathrm{C}$ for $30 \mathrm{sec}$, annealing at $60^{\circ} \mathrm{C}$ for $30 \mathrm{sec}$ and extension at $72^{\circ} \mathrm{C}$ for $40 \mathrm{sec}$, and a final extension step at $72^{\circ} \mathrm{C}$ for $5 \mathrm{~min}$. The pGL3-SV40 plasmid (Promega Corporation) containing the firefly luciferase gene driven by the SV40 promoter was used as a positive control. WP631 and mithramycin A were purchased from Sigma-Aldrich; Merck Millipore (Darmstadt, Germany). TNF- $\alpha$ and IL-1 $\beta$ were obtained from PeproTech, Inc. (Rocky Hill, NJ, USA). Rabbit anti-MMP3 (catalog no. ab52915) and rabbit anti-SDC4 (catalog no. ab24511) antibodies were purchased from Abcam (Cambridge, UK); rabbit anti-Cox2 (catalog no. 12282) and rabbit anti-Sp1 (catalog no. 9389) antibodies were obtained from Cell Signaling Technology, Inc. (Danvers, MA, USA); mouse anti-GAPDH (catalog no. AM4300) antibody was provided by Thermo Fisher Scientific, Inc. (Waltham, MA, USA); and mouse anti- $\beta$-tubulin (catalog no. N357) antibody and anti-mouse (catalog no. RPN4201) and anti-rabbit (catalog no. RPN4301) horseradish peroxidase (HRP)-conjugated IgG were purchased from GE Healthcare Life Sciences (Chalfont, UK).

Isolation, culture and treatment of NP cells. Consistent with the Institutional Review Board guidelines of Sun Yat-sen University (Guangzhou, China), human tissue samples were obtained from patients with thoracolumbar fractures undergoing spine fusion; informed consent for sample collection was obtained from each patient. A total of 8 male Sprague-Dawley rats (age, 2-3 months; weight, 220.3 $\pm 13.2 \mathrm{~g}$ ) were obtained from the Experimental Animal Center of Sun Yat-sen University. Rats were housed in specific pathogen-free conditions, at $19-28^{\circ} \mathrm{C}$ under a 12-h light/dark cycle and with ad libitum access to food and water. The Animal Care and Use Committee of the Sun Yat-sen University approved the experimental procedures.

Following anesthetisia with $10 \%$ chloral hydrate (Wuhan Hechang Chemical Co., Ltd., Wuhan, China) (>3.5 ml/kg), NP cells were isolated as described previously $(21,22)$. NP cells were cultured in Gibco Dulbecco's modified Eagle's medium (DMEM; Thermo Fisher Scientific, Inc.) with 10\% fetal bovine serum (FBS; Gibco; Thermo Fisher Scientific, Inc.) and antibiotics (100 U/ml penicillin and $100 \mathrm{U} / \mathrm{ml}$ streptomycin) at $37^{\circ} \mathrm{C}$ in a $5 \% \mathrm{CO}_{2}$ incubator. The medium was refreshed every 3 days. Following growth to $80 \%$ confluence, the NP cells were treated with $50 \mathrm{ng} / \mathrm{ml} \mathrm{TNF}-\alpha$ or $10 \mathrm{ng} / \mathrm{ml} \mathrm{IL-1} \beta$ for 4 , 8 or $24 \mathrm{~h}$, and cell RNA or protein extraction was performed. WP631 $(100 \mu \mathrm{M})$ or 1,000 nM mithramycin A were added $1 \mathrm{~h}$ prior to addition of cytokines.

Reverse transcription-quantitative PCR (RT-qPCR). Following the manufacturer's instructions, total RNA was extracted using TRIzol reagent (Invitrogen; Thermo Fisher Scientific, Inc.) and single-stranded cDNA was prepared by RT from 2,000 ng total RNA using Superscript III Reverse Transcriptase (Invitrogen; Thermo Fisher Scientific, Inc.) according to the manufacturer's protocol. Template cDNA and gene-specific primers were added into the Fast SYBR Green master mix (Applied Biosystems; Thermo Fisher Scientific, Inc.). A 7900HT Fast Real-Time PCR System (Applied Biosystems; Thermo Fisher Scientific, Inc.) was used and the cycling conditions were as follows: An initial denaturation step at $95^{\circ} \mathrm{C}$ for $5 \mathrm{~min}$ was followed by 40 cycles of denaturation at $95^{\circ} \mathrm{C}$ for $5 \mathrm{sec}$, annealing at $58^{\circ} \mathrm{C}$ for $10 \mathrm{sec}$ and extension at $72^{\circ} \mathrm{C}$ for $15 \mathrm{sec}$, and a final extension step at $72^{\circ} \mathrm{C}$ for $10 \mathrm{~min}$. mRNA expression was quantified using the standard curve method (23). Hypoxanthine phosphoribosyltransferase 1 and $\beta$-actin were used to normalize the expression of rat and human samples, respectively. Each sample was analyzed in duplicate. All primers were synthesized by Sangon Biotech Co., Ltd. (Shanghai, China), and are listed in Table I.

Western blotting. Following treatment, the NP cells and medium were collected and then treated with lysis buffer, containing 1X protease inhibitor cocktail (Roche Diagnostics, Basel, Switzerland), $\mathrm{NaCl}(5 \mathrm{mM}), \mathrm{NaF}(200 \mu \mathrm{M}), \mathrm{Na}_{3} \mathrm{VO}_{4}$ $(200 \mu \mathrm{M})$ and dithiothreitol $(0.1 \mathrm{mM})$. Following quantification by bicinchoninic acid assay, total cell proteins $(30 \mathrm{ng}$ ) were resolved by sodium dodecyl sulfate-polyacrylamide gels 
Table I. Primer sequences for quantitative polymerase chain reaction.

\begin{tabular}{llll}
\hline Species & \multicolumn{1}{c}{ Gene } & \multicolumn{1}{c}{ Sense (5' to 3') } & Anti-sense (5' to 3') \\
\hline Rat & MMP3 & CAGGGAAAGTGACCCACATATT & CGCCAAGTTTCAGAGGAAGA \\
& MMP13 & GAACCACGTGTGGAGTTATGA & GCATCTACTTTGTCGCCAATTC \\
& ADAMTS4 & GGAGATCGTGTTTCCAGAGAAG & CAAAGGCTGGTAATCGGTACA \\
& ADAMTS5 & GAATGTAGACCCTACAGCAACTC & CACACTCCACACTTGTCATACT \\
& Cox2 & TCAACCAGCAGTTCCAGTATC & GTGTACTCCTGGTCTTCAATGT \\
& SDC4, & CCCTTGGTGCACTAGATAAC & GACCTCATTCTCTTCCAGTTCC \\
& Sp1 & GAGGATGAGTAGACCAGCTTTG & TGGAAGAGGGAGTAGGAACTTA \\
& HPRT & GCTGACCTGCTGGATTACAT & CCCGTTGACTGGTCATTACA \\
& MMP3 & GCAAGACAGCAAGGCATAGA & CAGCAACAGTAGGATTGGAAGA \\
& AMP13 & GTTTGGTCCGATGTAACTCCTC & GAAGTCGCCATGCTCCTTAAT \\
& ADAMTS4 & GGTGGTGGTGATAGGTATAAGTG & TCAGGAAGAGGAAAGCAGAAC \\
& Cox2 & CTGCCACCACACTCAAGAA & TCCTCCCGAGTAAACAGGATAG \\
& SDC4, & CTATGTGCTAGCCCACAAAGA & GCATCCACAGATCCCTCAAA \\
& Sp1 & GACTGGGATTGGATCACTTCTT & ACTCCACACAACATCCGTTAG \\
& B-actin & TCCAAGGCCTGGCTAATAATG & GACAGGTAGCAAGGTGATGTT \\
& & GGACCTGACTGACTACCTCAT & CGTAGCACAGCTTCTCCTTAAT \\
\hline
\end{tabular}

on $10 \%$ gels, then transferred by electroblotting to polyvinylidene difluoride membranes (Bio-Rad Laboratories, Inc., Hercules, CA, USA). Membranes were blocked in 5\% non-fat dry milk for $1 \mathrm{~h}$ at room temperature in Tris-buffered saline (50 mM Tris, pH 7.6, $150 \mathrm{mM} \mathrm{NaCl}$ ) plus $0.1 \%$ Tween-20 and incubated overnight at $4^{\circ} \mathrm{C}$ with the primary antibody $(1: 1,000$ anti-MMP3; 1:1,000 anti-Cox2; 1:1,000 anti-SDC4; 1:1,000 anti-Sp1; 1:3,000 anti-GAPDH; or 1:3,000 anti- $\beta$-tubulin). Membranes were then incubated with HRP-conjugated anti-rabbit or anti-mouse $\operatorname{IgG}(1: 2,000-1: 5,000)$ for $1 \mathrm{~h}$ and the signals detected using enhanced chemiluminescence (GE Healthcare Life Sciences). GAPDH and $\beta$-tubulin were used as protein loading controls for rat and human samples, respectively. Protein bands were quantified by densitometric analysis using Kodak 1D software version 3.6 (Kodak, Rochester, NY, USA).

Transfections and dual-luciferase reporter assay. Rat NP cells were seeded in 48 -well plates at a density of $3 \times 10^{4}$ cells $/ \mathrm{ml}$ with 2\% Opti-Minimal Essential Medium Reduced Serum (Gibco; Thermo Fisher Scientific, Inc.). The following day, cells were transfected using Lipofectamine ${ }^{\circledR} 2000$ (Invitrogen; Thermo Fisher Scientific, Inc.), 250 ng MMP3, ADAMTS4 or ADAMTS5 promoter luciferase reporter plasmids and $250 \mathrm{ng}$ of the internal control plasmid, pRL-TK. Cells were stimulated with WP631 $(100 \mu \mathrm{M})$ or mithramycin A $(1,000 \mathrm{nM}) 48 \mathrm{~h}$ post-transfection. Cells were harvested $24 \mathrm{~h}$ later, and firefly and Renilla luciferase activities were measured using the Dual Luciferase Reporter Assay Kit (Promega Corporation) according to the manufacturer's instructions.

Lentivirus production and transduction. HEK 293T human embryonic kidney cells were seeded in a humidified incubator at $37^{\circ} \mathrm{C}, 5 \% \mathrm{CO}_{2}$ at a density of $3 \times 10^{6}$ cells per $10 \mathrm{~cm}$ plate in DMEM with $10 \%$ heat-inactivated FBS. Following $\sim 24 \mathrm{~h}$ incubation, cells were transfected with lentiviral vectors and packaging plasmids (psPAX2 and pMD2.G) using Lipofectamine 2000 reagent (Invitrogen; Thermo Fisher Scientific, Inc.) according to the manufacturer's instructions. Following $16 \mathrm{~h}$ incubation, the transfection medium was replaced with DMEM with $10 \%$ heat-inactivated FBS. At 48 and $60 \mathrm{~h}$ post-transfection, the supernatant was harvested from HEK 293T human embryonic kidney cells and was introduced into human NP cell cultures $\left(0.5 \times 10^{6}\right.$ cells/plate $)$ with $6 \mathrm{mg} / \mathrm{ml}$ Polybrene (EMD Millipore, Billerica, MA, USA). A total of $24 \mathrm{~h}$ later, the medium containing viral particles was removed and replaced with DMEM containing $10 \%$ FBS and antibiotics. Cells and medium were harvested from NP cells 5 days later for mRNA or protein extraction.

Chromatin immunoprecipitation (ChIP). The ChIP assay was performed as described previously $(21,22)$. Briefly, human NP cells were cultured in DMEM media supplemented with $10 \%$ FBS to $80 \%$ confluence. The cells were then cross-linked, lysed and the chromatin was sheared by sonication. Input DNA was generated by treating aliquots with RNase, proteinase $\mathrm{K}$, and heat, followed by ethanol precipitation. DNA complexes were immunoprecipitated overnight using antibodies for $\mathrm{Sp} 1$ and nonspecific rabbit $\mathrm{IgG}$ followed by binding to protein $\mathrm{G}$-agarose beads. Cross-links were reversed by treatment with proteinase $\mathrm{K}$ and heat, and the DNA was purified using DNA purification elution buffer (Active Motif, Carlsbad, CA, USA). qPCR analysis was performed using a ChIP-IT quantitative PCR analysis kit (cataolog no. 53040; Active Motif) using the following primer pairs for putative Sp1 sites within the ADAMTS4 and ADAMTS5 promoters: (-577/-567) ADMATS4 motif, 5'-CTATTATCCATTCGG CTGCTAGA-3' (sense) and 5'-ATGGGTGTATCATCGCTT CC-3' (anti-sense); and -718/-708 ADAMTS5 motif, 5'-TTA 
AGAGGCAGCGTGCAG-3' (sense) and 5'-GCGAGCGCT GTGAAGAT-3' (anti-sense). The negative control primers were purchased from Active Motif (catalog no. 71001).

Statistical analysis. All experiments were repeated independently at least three times. Data are presented as the mean \pm standard error. Statistical analyses were performed in SPSS software version 13.0 (SPSS, Inc., Chicago, IL, USA). Differences between groups were analyzed by one-way analysis of variance, followed by the post hoc tests Student-Newman-Keuls and least significant difference. $\mathrm{P}<0.05$ was considered to indicate a statistically significant difference.

\section{Results}

Treatment with Spl inhibitors attenuates catabolic gene expression induced by TNF- $\alpha$. To observe the effect of Sp1 and GC-rich island inhibitors on the expression of the catabolic enzyme genes MMP3, ADAMTS4 and Cox 2, $1 \mathrm{~h}$ prior to TNF- $\alpha$ stimulation, the NP cells were treated with WP631 and mithramycin $\mathrm{A}$, which serve as transcriptional inhibitors by displacing Sp1 from promoters by binding to GC-rich DNA motifs. The data revealed that MMP3, MMP13, ADAMTS4, ADAMTS5, Cox 2 and SDC4 mRNA expression was significantly increased following stimulation with TNF- $\alpha$ compared with untreated controls $(\mathrm{P}<0.05)$, whereas the mRNA expression was significantly decreased following treatment with WP631 or mithramycin A compared with TNF- $\alpha$ treatment only $(\mathrm{P}<0.05$; Fig. 1A). Furthermore, western blot results revealed that stimulation with TNF- $\alpha$ significantly increased the intracellular protein expression of MMP3, Cox 2 and SDC4 and the protein expression of MMP3 in the medium compared with unstimulated cells $(\mathrm{P}<0.05$; Fig. 1B). However, treatment with WP631 or mithramycin A significantly suppressed this increased expression ( $\mathrm{P}<0.05$; Fig. 1B).

Sp1 transcription factor controls MMP3, ADAMTS4 and ADAMTS5 promoter activities in NP cells. To further confirm the involvement of Sp1 in the regulation of catabolic factors, the luciferase activity of pGL3 firefly luciferase reporter constructs containing the promoter region of MMP3, ADAMTS4 and ADAMTS5 was assessed following stimulation with TNF- $\alpha$ or IL-1 $\beta$, and treatment with WP631 or mithramycin A. Stimulation with TNF- $\alpha$ and IL-1 $\beta$ resulted in significantly increased MMP3 promoter activity compared with unstimulated rat NP cells $(\mathrm{P}<0.05)$, while WP631 and mithramycin A significantly suppressed this MMP3 promoter induction ( $\mathrm{P}<0.05$; Fig. 2A). TNF- $\alpha$ and IL-1 $\beta$ stimulation had no significant effect on ADAMTS4 and ADAMTS5 promoter activities (Fig. 2B and C), despite TNF- $\alpha$ stimulation having been demonstrated to increase ADAMTS4 and ADAMTS5 mRNA and protein expression levels (Fig. 1). However, treatment with WP631 and mithramycin A did result in significantly reduced ADAMTS4 and ADAMTS5 promoter activity compared with untreated cells that had been stimulated with TNF- $\alpha$ or IL-1 $\beta$ ( $\mathrm{P}<0.05$; Fig. 2B and C, respectively).

To determine whether Sp1 binds to the catabolic gene promoters, ChIP analysis was performed to assess $\mathrm{Sp} 1$ binding to the cognate $\mathrm{Sp} 1$ motifs in the promoter regions of
A
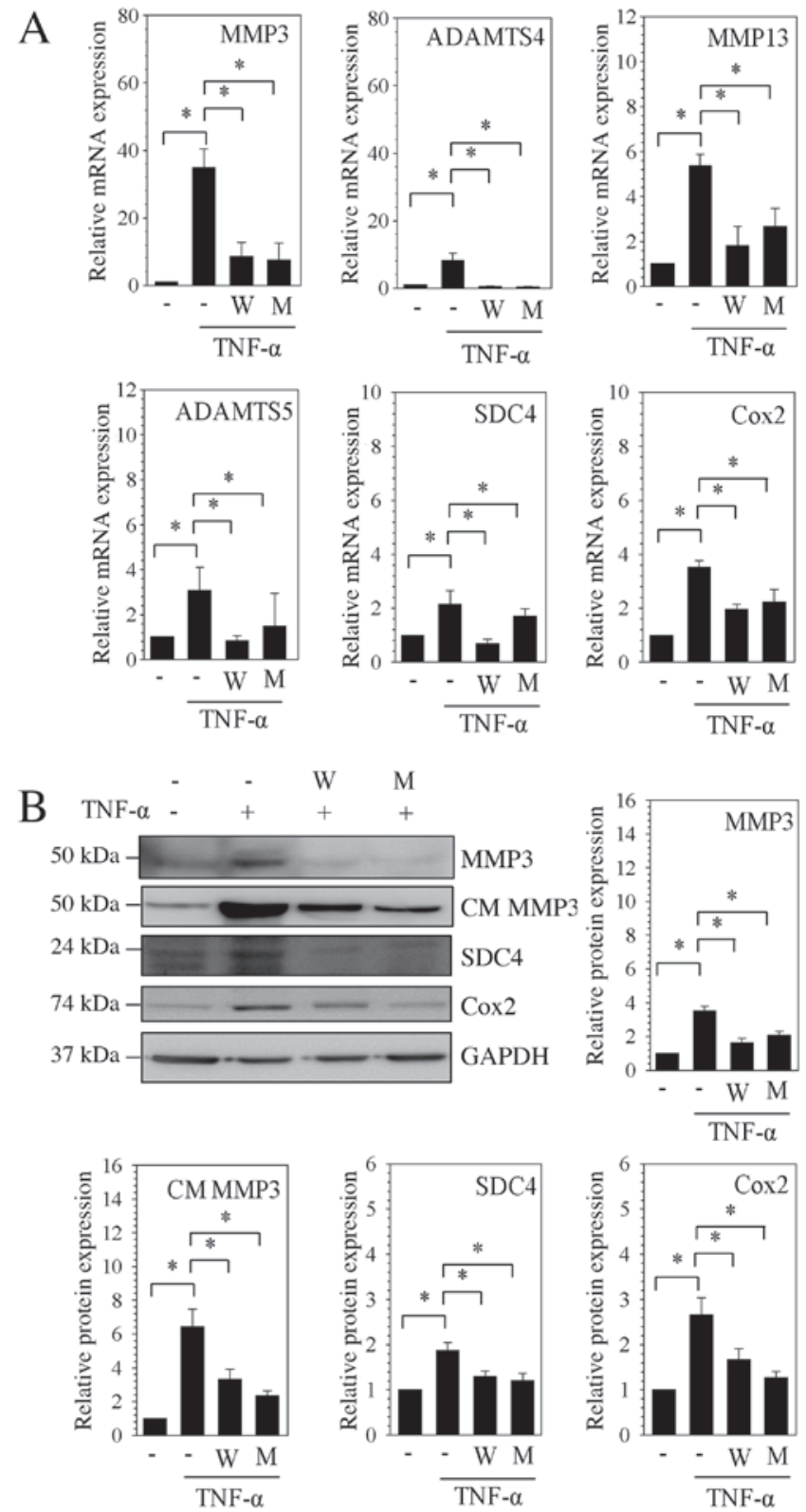

Figure 1. Expression of catabolic factors induced by TNF- $\alpha$ in nucleus pulposus cells was suppressed by specificity protein-1 transcription factor inhibitors. (A) mRNA expression levels of MMP3, ADAMTS4, MMP13, ADAMTS5, SDC4 and Cox 2 were assessed by reverse transcription-quantitative polymerase chain reaction following stimulation with TNF- $\alpha$, and treatment with WP631 or mithramycin A. (B) Western blot analysis of protein expression levels of MMP3, CM MMP3, Cox2 and SDC4, following stimulation with TNF- $\alpha$ and treatment with WP631 or mithramycin A. Densitometric quantification was relative to GAPDH. Data are presented as the mean \pm standard error of three independent experiments performed in triplicate, relative to the unstimulated control; ${ }^{*} \mathrm{P}<0.05$, comparison indicated by brackets. MMP, matrix metalloproteinases; W, WP631; M, mithramycin A; TNF- $\alpha$, tumor necrosis factor- $\alpha$; ADAMTSs, disintegrins and metalloproteinases with thrombospondin motifs; SDC4, syndecan 4; Cox 2, cyclooxygenase 2; CM, conditioned medium; GAPDH, glyceraldehyde 3-phosphate dehydrogenase.

ADAMTS4 and ADAMTS5. As presented in Fig. 2D, using the Sp1 antibody for ChIP resulted in $\sim 3.6$-fold enrichment in binding of Sp1 to a site located at $-577 /-567 \mathrm{bp}$ in the human ADAMTS4 promoter compared with the $\mathrm{IgG}$ control ( $\mathrm{P}=0.039$; Fig. 2D), while 6.1-fold enrichment of Sp1 binding compared with $\operatorname{IgG}$ control was detected at the motif located 

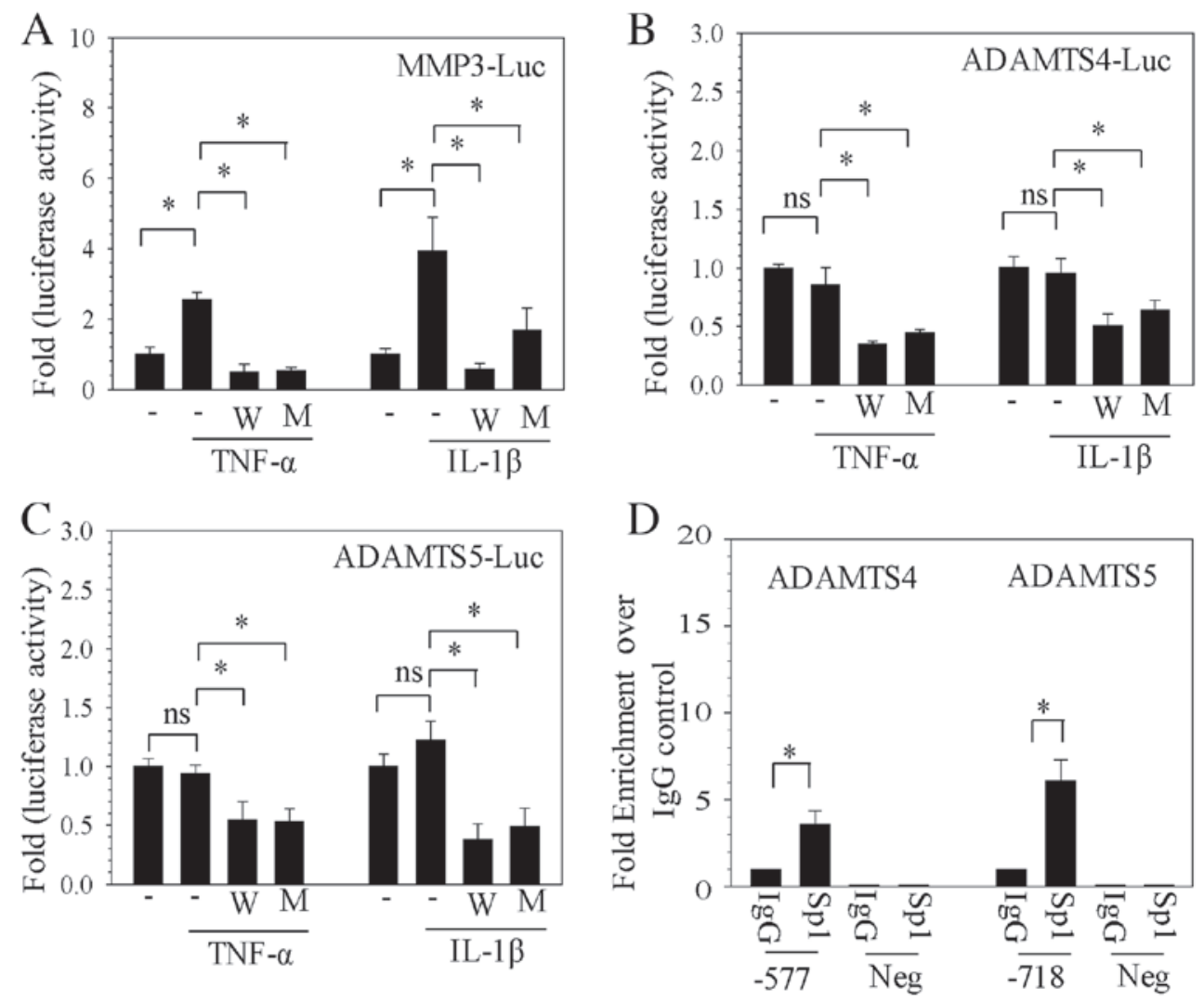

Figure 2. Sp1 controls catabolic factor promoter activity in NP cells. Firefly luciferase was used as a reporter of transcriptional regulation of the promoter regions of (A) MMP3, (B) ADAMTS4 and (C) ADAMTS5, following stimulation with TNF- $\alpha$ or IL-1 $\beta$ and treatment with WP631 or mithramycin A. (D) Sp1 binding to Sp1 motifs at -577/-567 bp of ADAMTS4 and -718/-708 bp ADAMTS5 promoters in human NP cells was analyzed by genomic chromatin immunoprecipitation analysis with $\mathrm{Sp} 1$ and $\mathrm{IgG}$ antibody pulldowns. Negative primers revealed minimal amplification from experimental and IgG control samples. Data are presented as the mean \pm standard error of three independent experiments performed in triplicate. ${ }^{*} \mathrm{P}<0.05$, comparison indicated by brackets Sp1, specificity protein-1 transcription factor; NP, nucleus pulposus; MMP, matrix metalloproteinases; Luc, luciferase; W, WP631; M, mithramycin A; TNF- $\alpha$, tumor necrosis factor- $\alpha$; IL-1 $\beta$, interleukin-1 $\beta$; ADAMTSs, disintegrins and metalloproteinases with thrombospondin motifs; IgG, immunoglobulin G; Neg, negative control primers.

at $-718 /-708$ bp in the human ADAMTS5 promoter $(\mathrm{P}=0.027$; Fig. 2D). Negative control primers demonstrated almost undetectable amplification (Fig. 2D).

Regulation of Spl mRNA and protein following TNF- $\alpha$ and $I L-1 \beta$ stimulation. To determine the effect of cytokine stimulation on the expression of Sp1 mRNA and protein, NP cells were stimulated with TNF- $\alpha$ and IL-1 $\beta$. Sp1 mRNA expression levels remained unchanged at 4,8 and $24 \mathrm{~h}$ following stimulation with TNF- $\alpha$ (Fig. 3A) and IL-1 $\beta$ (Fig. 3B), compared with unstimulated control cells. However, $\mathrm{Sp} 1$ protein expression levels were significantly higher following $24 \mathrm{~h} \mathrm{TNF-} \alpha$ stimulation compared with the unstimulated control $(\mathrm{P}=0.040$; Fig. $3 \mathrm{C}$ and D), and were significantly higher following 8 and $24 \mathrm{~h}$ of IL-1 $\beta$ stimulation compared with the unstimulated control $(\mathrm{P}=0.039$ and $\mathrm{P}=0.048$, respectively; Fig. $3 \mathrm{C}$ and $\mathrm{D})$.

Stable silencing of Spl decreases catabolic gene expression induced by TNF- $\alpha$. To further examine whether the Sp1 transcription factor controls catabolic gene expression in human NP cells, Sp1 loss-of-function studies were performed using lentiviral delivery of gene-targeting shRNA. As observed in rat NP cells, no significant difference in Sp1 mRNA expression was observed in response to stimulation with TNF- $\alpha$ in human NP cells transduced with control shRNA compared with unstimulated cells transduced with control shRNA (Fig. 4A). mRNA expression levels in human NP cells stimulated with TNF- $\alpha$ and transduced with Spl shRNA were $\sim 78 \%$ reduced, compared with $\mathrm{TNF}-\alpha$-stimulated cells transduced with control shRNA ( $\mathrm{P}=0.001$; Fig. 4A). In TNF- $\alpha$-stimulated NP cells in which Sp1 was suppressed (cells transduced with Sp1 shRNA), MMP3, MMP13, ADAMTS4, ADAMTS5 and SDC4 mRNA expression was significantly reduced compared with TNF- $\alpha$-stimulated cells transduced with control shRNA $(\mathrm{P}<0.05$; Fig. 4A). Furthermore, western blot analysis was used to investigate protein expression levels of Sp1, the cell protein, Cox2, and condition medium MMP3 in Sp1-silenced cells (cells transduced with Sp1 shRNA). Sp1 protein expression was significantly reduced in cells transduced with $\mathrm{Sp} 1 \mathrm{shRNA}$ and stimulated with TNF- $\alpha$ compared with TNF- $\alpha$-stimulated cells transduced with control shRNA ( $\mathrm{P}=0.001$; Fig. 4B). Consistent with the changes in mRNA expression levels of catabolic genes, including MMP3 and ADAMTS4, Cox2 expression and the level of MMP3 protein in the medium in cells transduced with Sp1 shRNA and stimulated with TNF- $\alpha$ was $\sim 58$ and $~ 44 \%$ lower than in TNF- $\alpha$-stimulated cells transduced with control shRNA $(\mathrm{P}=0.023$ and $\mathrm{P}=0.032$, respectively; Fig. 4B). 
A

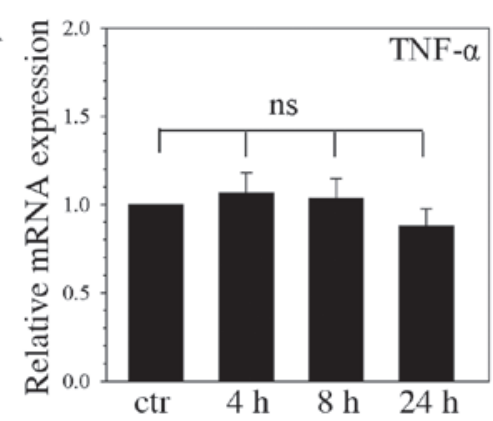

$\mathrm{C}$

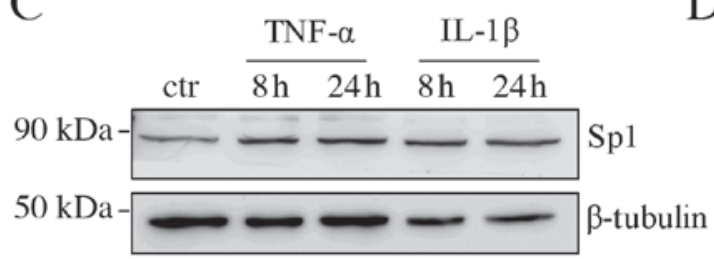

$\mathrm{B}$

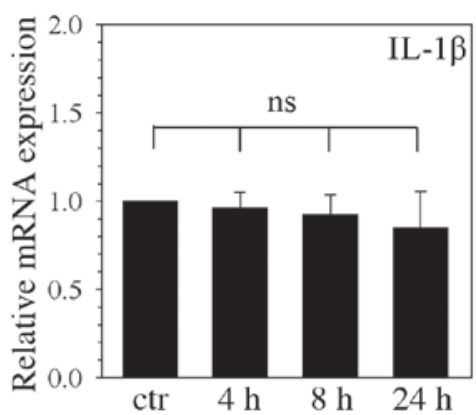

$\mathrm{D}$

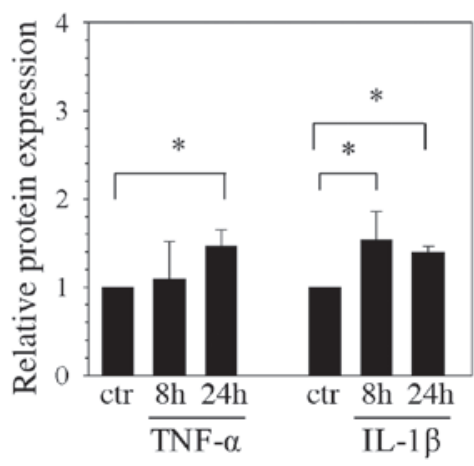

Figure 3. Sp1 mRNA and protein expression levels following the cytokines stimulation of nucleus pulposus cells. Sp1 mRNA expression levels following stimulation with (A) TNF- $\alpha$ and (B) IL-1 $\beta$. (C) Sp1 protein expression was assessed by western blot following stimulation with TNF- $\alpha$ and IL-1 $\beta$, and (D) quantification normalized to $\beta$-tubulin. Data are presented as the mean \pm standard error of three independent experiments performed in triplicate, relative to the unstimulated control; ${ }^{P} \mathrm{P}<0.05$, comparison indicated by brackets. Sp1, specificity protein-1 transcription factor; TNF- $\alpha$, tumor necrosis factor- $\alpha$; IL-1 $\beta$, interleukin-1 $\beta$; ns, no significance.

\section{Discussion}

The experiments described in the present study demonstrated that in NP cells, Sp1 transcription factor inhibitors and knockdown suppressed the TNF- $\alpha$-induced expression of the catabolic factors MMP3, ADAMTS-4, Cox2 and SDC4. Furthermore, Sp1 was essential for the maintenance of catabolic factor transcriptional expression due to direct interaction with cognate binding sites in their promoters. In addition, Sp1 transcription factor protein expression is induced by stimulation with inflammatory cytokines in NP cells.

Intervertebral disc degeneration is generally believed to be a consequence of increased catabolism of the ECM. Over the last decade, the research on intervertebral disc degeneration has emphasized the mechanism of ECM degradation. MMPs, ADAMTSs and Cox 2 have been proposed to be the major catabolic enzymes in the intervertebral disc $(8,24)$. SDC4, a cell-surface heparan sulfate proteoglycan, participates in inflammation and mediates the expression of MMP3, ADAMTS4 and ADAMTS5 in NP cells $(4,5,8)$. TNF- $\alpha$ induces the expression of catabolic factors including MMP3, MMP13, ADAMTS4, ADAMTS5, Cox2 and SDC4 in NP cells and articular chondrocytes $(3,5,6,8,9,21,25,26)$. $\mathrm{Sp} 1$ is also involved in the expression of ECM-related genes in various cells $(15,16)$. The present study revealed that the expression of Sp1 mRNA was unaffected by TNF- $\alpha$ and IL-1 $\beta$ stimulation in human and rat NP cells, as previously reported in bovine NP cells (27). However, Sp1 protein expression was induced by TNF- $\alpha$ and IL-1 $\beta$ stimulation, as reported in articular chondrocytes (28). In articular chondrocytes, Sp1 mediates the inductive activity of TNF- $\alpha$ (29-31). To the best of our knowledge, the present study presents the first evidence that the Sp1 inhibitors, WP631 and mithramycin A, suppress the TNF- $\alpha$-induced expression of catabolic factors in NP cells. Furthermore, loss of function experiments also revealed that Sp1 knockdown decreased cytokine-induced expression of MMP3, MMP13, ADAMTS4, ADAMTS5, Cox 2 and SDC4 in NP cells.

There are numerous Sp1 binding sites in MMPs, ADAMTSs, Cox 2 and SDC4 promoters $(17,18,32,33)$, but the present study limited its investigations to MMP3, ADAMTS4 and ADAMTS5 promoter constructs containing Sp1 sites. Stimulation of NP cells with TNF- $\alpha$ and IL- $1 \beta$ resulted in increased expression from MMP3 promoter constructs, as previously reported (10), however, $\mathrm{Sp1}$ inhibitors suppressed the induction by TNF- $\alpha$ or IL- $1 \beta$. Although TNF- $\alpha$ and IL-1 $\beta$ stimulation had no effect on transcription from the ADAMTS4 and ADAMTS5 promoters, this may have been due to the promoter constructs being too short or lacking effective binding sites for TNF- $\alpha$ downstream mediators. However, Sp1 inhibitors reduced the baseline activity of ADAMTS4 and ADAMTS5 promoter constructs during stimulation with TNF- $\alpha$ and IL-1 $\beta$. To further support the functional studies of ADAMTS4 and ADAMTS5 promoter constructs, genomic ChIP analysis demonstrated that the enriched binding of Sp1 to the ADAMTS4 and ADAMTS5 promoter fragment that contained the $-577 /-567$ and 718/-708 bp binding sites, respectively, controls its basal transcription. The present study therefore revealed that TNF- $\alpha$ induces increased ADAMTS4 and ADAMTS5 mRNA expression, but did not affect transcription from the ADAMTS4 and ADAMTS5 promoter reporter constructs. 
A
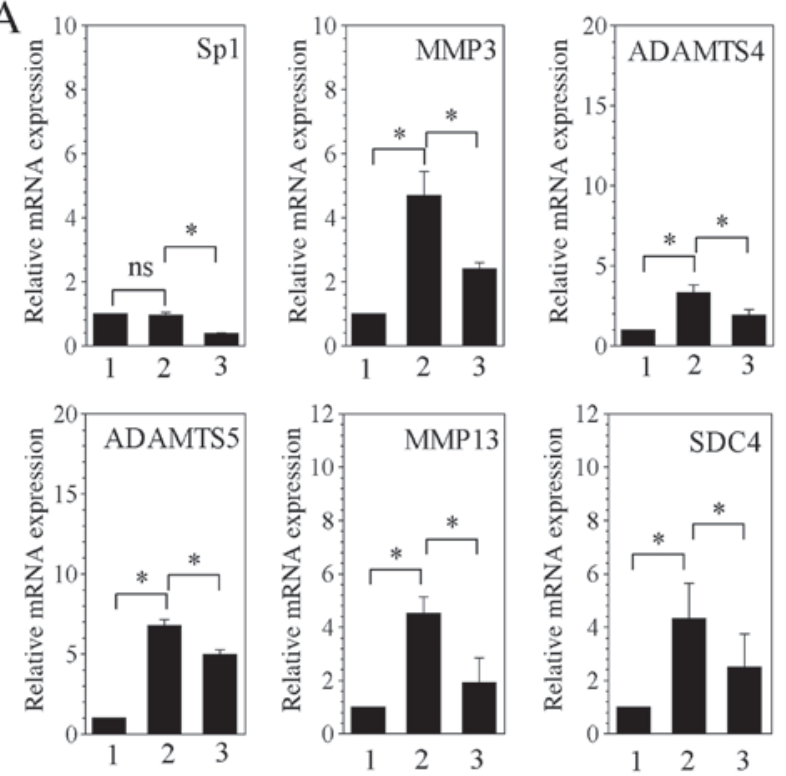

B
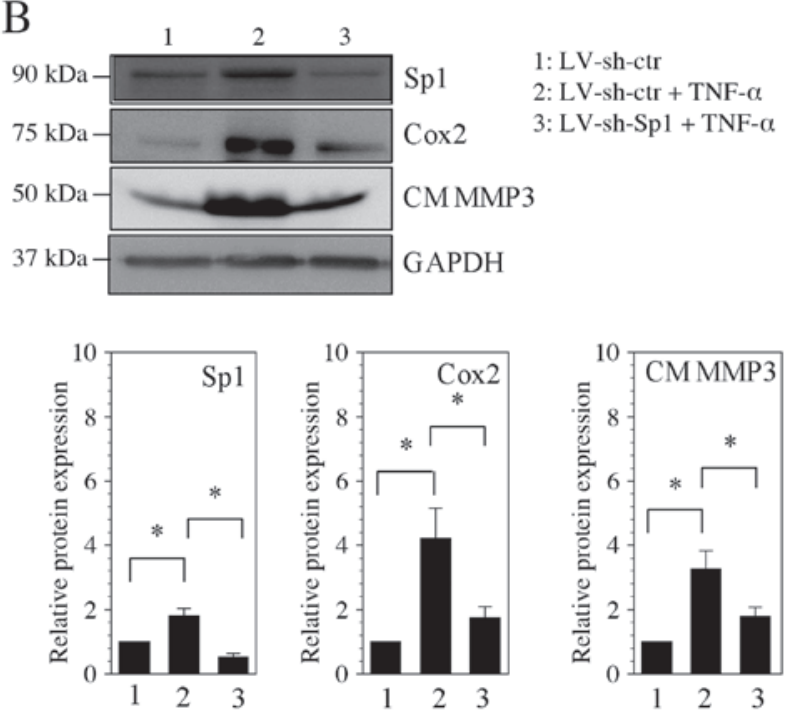

Figure 4. Stable silencing of $\mathrm{Spl}$ decreases catabolic factors induction by TNF- $\alpha$ in human NP cells. (A) mRNA expression levels of Sp1, MMP3, ADAMTS4, ADAMTS5, MMP13 and SDC4 were assessed by reverse transcription-quantitative polymerase chain reaction following lentiviral transfection and stimulation with TNF- $\alpha$. (B) Western blot analysis of protein expression levels of Sp1, Cox2 and CM MMP3 following lentiviral transfection and stimulation with TNF- $\alpha$, with quantification relative to GAPDH. Data are presented as the mean \pm standard error of three independent experiments performed in triplicate, relative to $\mathrm{LV}$-sh-ctr. ${ }^{*} \mathrm{P}<0.05$, comparison indicated by brackets. Sp1, specificity protein-1 transcription factor; ns, no significance; MMP, matrix metalloproteinase; ADAMTSs, disintegrins and metalloproteinases with thrombospondin motifs; SDC4, syndecan 4; LV, lentivirus; sh, short hairpin RNA; ctr, control; TNF- $\alpha$, tumor necrosis factor- $\alpha$ Cox 2, cyclooxygenase 2; CM, conditioned medium; GAPDH, glyceraldehyde 3-phosphate dehydrogenase.

The pharmacological and genetic evidence presented in the present study demonstrated that Spl is involved in the TNF- $\alpha$-induced expression of catabolic factors, including MMP3 and ADAMTS4. Therapeutic targeting of the Sp1 transcription factor to block the activity these catabolic factors may therefore present a novel strategy to prevent degradation of intervertebral discs by catabolic factors during the pathogenesis of intervertebral disc degeneration.

\section{Acknowledgements}

This work was supported by grants from the National Natural Science Foundation of China (grant nos. 81101385 and 81572197), the Natural Science Foundation of Guangdong Province, China (grant no. 2016A030313189) and the Science and Technology Planning Project of Guangdong Province (grant nos. 2012B031800359, 2012B031800360 and 2014A020212058).

\section{References}

1. Stemple DL: Structure and function of the notochord: An essential organ for chordate development. Development 132: 2503-2512, 2005.

2. Feng H, Danfelter M, Strömqvist B and Heinegård D: Extracellular matrix in disc degeneration. J Bone Joint Surg Am 88 (Suppl 2): S25-S29, 2006.

3. Roughley PJ: Biology of intervertebral disc aging and degeneration: Involvement of the extracellular matrix. Spine (Phila Pa 1976) 29: 2691-2699, 2004.

4. Boos N, Weissbach S, Rohrbach H, Weiler C, Spratt KF and Nerlich AG: Classification of age-related changes in lumbar intervertebral discs: 2002 Volvo Award in basic science. Spine (Phila Pa 1976) 27: 2631-2644, 2002.

5. Podichetty VK: The aging spine: The role of inflammatory mediators in intervertebral disc degeneration. Cell Mol Biol (Noisy-le-grand) 53: 4-18, 2007.

6. Tian Y, Yuan W, Fujita N, Wang J, Wang H, Shapiro IM and Risbud MV: Inflammatory cytokines associated with degenerative disc disease control aggrecanase-1 (ADAMTS-4) expression in nucleus pulposus cells through MAPK and NF-кB. Am J Pathol 182: 2310-2321, 2013.

7. Wang J, Markova D, Anderson DG, Zheng Z, Shapiro IM and Risbud MV: TNF- $\alpha$ and IL-1 $\beta$ promote a disintegrin-like and metalloprotease with thrombospondin type I motif-5-mediated aggrecan degradation through syndecan-4 in intervertebral disc. J Biol Chem 286: 39738-39749, 2011.

8. Vo NV, Hartman RA, Yurube T, Jacobs LJ, Sowa GA and Kang JD: Expression and regulation of metalloproteinases and their inhibitors in intervertebral disc aging and degeneration. Spine J 13: 331-341, 2013.

9. Jimbo K, Park JS, Yokosuka K, Sato K and Nagata K: Positive feedback loop of interleukin-1beta upregulating production of inflammatory mediators in human intervertebral disc cells in vitro. J Neurosurg Spine 2: 589-595, 2005.

10. Wang X, Wang H, Yang H, Li J, Cai Q, Shapiro IM and Risbud MV: Tumor necrosis factor- $\alpha$ - and interleukin-1 $\beta$-dependent matrix metalloproteinase- 3 expression in nucleus pulposus cells requires cooperative signaling via syndecan 4 and mitogen-activated protein kinase-NF- $\kappa$ B axis: Implications in inflammatory disc disease. Am J Pathol 184: 2560-2572, 2014.

11. Studer RK, Aboka AM, Gilbertson LG, Georgescu H, Sowa G, Vo N and Kang JD: p38 MAPK inhibition in nucleus pulposus cells: A potential target for treating intervertebral disc degeneration. Spine (Phila Pa 1976) 32: 2827-2833, 2007.

12. Lin TH, Tang CH, Wu K, Fong YC, Yang RS and Fu WM: 15-deox $\mathrm{y}-\Delta(12,14)$-prostaglandin-J2 and ciglitazone inhibit TNF- $\alpha$-induced matrix metalloproteinase 13 production via the antagonism of $\mathrm{NF}-\kappa \mathrm{B}$ activation in human synovial fibroblasts. J Cell Physiol 226: 3242-3250, 2011.

13. Park HY, Kim TH, Kim CG, Kim GY, Kim CM, Kim ND, Kim BW, Hwang HJ and Choi YH: Purpurogallin exerts anti-inflammatory effects in lipopolysaccharide-stimulated BV2 microglial cells through the inactivation of the NF- $\kappa \mathrm{B}$ and MAPK signaling pathways. Int J Mol Med 32: 1171-1178, 2013.

14. Kadonaga JT, Courey AJ, Ladika J and Tjian R: Distinct regions of Sp1 modulate DNA binding and transcriptional activation. Science 242: 1566-1570, 1988.

15. Jiang L, Zhou Y, Xiong M, Fang L, Wen P, Cao H, Yang J, Dai C and He W: Spl mediates microRNA-29c-regulated type I collagen production in renal tubular epithelial cells. Exp Cell Res 319: 2254-2265, 2013.

16. Domenzain-Reyna C, Hernández D, Miquel-Serra L, Docampo MJ, Badenas C, Fabra A and Bassols A: Structure and regulation of the versican promoter: The versican promoter is regulated by AP-1 and TCF transcription factors in invasive human melanoma cells. J Biol Chem 284: 12306-12317, 2009. 
17. Sylvester J, Ahmad R and Zafarullah M: Role of Sp1 transcription factor in Interleukin-1-induced ADAMTS-4 (aggrecanase-1) gene expression in human articular chondrocytes. Rheumatol Int 33: 517-522, 2013.

18. Xu K and Shu HK: Transcription factor interactions mediate EGF-dependent COX-2 expression. Mol Cancer Res 11: 875-886, 2013.

19. Yang WJ, Song MJ, Park EY, Lee JJ, Park JH, Park K, Park JH and Kim HP: Transcription factors $\mathrm{Sp1}$ and $\mathrm{Sp} 3$ regulate expression of human ABCG2 gene and chemoresistance phenotype. Mol Cells 36: 368-375, 2013.

20. Wang SC, Lin XL, Li J, Zhang TT, Wang HY, Shi JW, Yang S, Zhao WT, Xie RY, Wei F, et al: MicroRNA-122 triggers mesenchymal-epithelial transition and suppresses hepatocellular carcinoma cell motility and invasion by targeting RhoA. PLoS One 9: e101330, 2014.

21. Ye W, Zhou J, Markova DZ, Tian Y, Li J, Anderson DG, Shapiro IM and Risbud MV: Xylosyltransferase-1 expression is refractory to inhibition by inflammatory cytokines tumor necrosis factor $\alpha$ and IL-1 $\beta$ in nucleus pulposus cells: Novel regulation by AP-1, Sp1, and Sp3. Am J Pathol 185: 485-495, 2015.

22. Soutoglou E and Talianidis I: Coordination of PIC assembly and chromatin remodeling during differentiation-induced gene activation. Science 295: 1901-1904, 2002.

23. Johnson GL, Bibby DF, Wong S, Agrawal SG and Bustin SA: A MIQE-compliant real time PCR assay for Aspergillus detection. PLoS One 7: e40022, 2012.

24. Wang WJ, Yu XH, Wang C, Yang W, He WS, Zhang SJ, Yan YG and Zhang J: MMPs and ADAMTSs in intervertebral disc degeneration. Clin Chim Acta 448: 238-446, 2015.

25. Xu K, Chen W, Wang X, Peng Y, Liang A, Huang D, Li C and Ye W: Autophagy attenuates the catabolic effect during inflammatory conditions in nucleus pulposus cells, as sustained by NF- $\kappa \mathrm{B}$ and JNK inhibition. Int J Mol Med 36: 661-668, 2015.
26. Echtermeyer F, Bertrand J, Dreier R, Meinecke I, Neugebauer K, Fuerst M, Lee YJ, Song YW, Herzog C, Theilmeier G and Pap T: Syndecan-4 regulates ADAMTS-5 activation and cartilage breakdown in osteoarthritis. Nat Med 15: 1072-1076, 2009.

27. Séguin CA, Pilliar RM, Roughley PJ and Kandel RA: Tumor necrosis factor-alpha modulates matrix production and catabolism in nucleus pulposus tissue. Spine (Phila $\mathrm{Pa}$ 1976) 30: 1940-1948, 2005.

28. Séguin CA, Pilliar RM, Madri JA and Kandel RA: TNF-alpha induces MMP2 gelatinase activity and MT1-MMP expression in an in vitro model of nucleus pulposus tissue degeneration. Spine (Phila Pa 1976) 33: 356-365, 2008

29. Liacini A, Sylvester J, Li WQ and Zafarullah M: Mithramycin downregulates proinflammatory cytokine-induced matrix metalloproteinase gene expression in articular chondrocytes. Arthritis Res Ther 7: R777-R783, 2005.

30. Hashimoto K, Otero M, Imagawa K, de Andrés MC, Coico JM, Roach HI, Oreffo RO, Marcu KB and Goldring MB: Regulated transcription of human matrix metalloproteinase 13 (MMP13) and interleukin-1 $\beta$ (IL-1B) genes in chondrocytes depends on methylation of specific proximal promoter CpG sites. J Biol Chem 288: 10061-10066, 2013.

31. Wu N, Opalenik S, Liu J, Jansen ED, Giro MG and Davidson JM: Real time visualization of MMP-13 promoter activity in transgenic mice. Matrix Biol 21: 149-161, 2002.

32. Mizui Y, Yamazaki K, Kuboi Y, Sagane K and Tanaka I: Characterization of 5'-flanking region of human aggrecanase-1 (ADAMTS4) gene. Mol Biol Rep 27: 167-173, 2000.

33. Chuang CW, Pan MR, Hou MF and Hung WC: Cyclooxygenase-2 up-regulates CCR7 expression via AKT-mediated phosphorylation and activation of Sp1 in breast cancer cells. J Cell Physiol 228: 341-348, 2013. 